THURSDAY, FEBRUARY 16, 187I

\section{THE EDUCATION OF CIVIL ENGINEERS}

$\mathrm{A}^{\mathrm{T}}$

TTENTION has been called to this important subject by a pamphlet recently issued by the Institution of Civil Engineers, containing a clear and well-digested account of the education and status of engineers at home and abroad. The pamphlet, however, is more remarkable for its omissions than for its contents, among which we find premisses warranting a conclusion or many conclusions concerning the education and position of the engineer in different countries. The documents which have been employed in its compilation have been collected, arranged, and issued, under the supervision of the Council of the Jnstitution of Civil Engineers, a body most able to draw conclusions, and to give practical effect to any resolution they may adopt, and yet no conclusion whatever is drawn, and no resolution whatever is adopted. Perhaps, indeed, the Council consider that the education of engineers in England cannot be improved ; this interpretation may easily be given to the short summary given of the English system, contained in the following passages:--

There is, further, in England no public provision for engineering education. Every candidate for the profession must get his technical, like his general education, as best he can; and this necessity has led to conditions of education peculiarly and essentially practical, such being the most direct and expeditious mode of getting into the way of practical employment.

The education of an engineer is, in fact, effected by a process analogous to that followed generally in trades, namely, by a simple course of apprenticeship, usually with a premium, to a practising engineer; during which the pupil is supposed, by taking part in the ordinary business routine, to become gradually familiar with the practical duties of the profession, so as at least to acquire competency to perform them alone, or, at least, after some further practical experience in a subordinate capacity.

It is not the custom in England to consider theorelical knowledge as absolutely essential. It is true that most considerate masters recommend that such knowledge should be acquired, and prefer such pupils as have in some degree attained it, and it is also true that intelligent and earnest-minded pupils often spontaneously devote themselves, both before and during their pupilage, to theoretical studies; but these cases, though happily much more frequent now than formerly, really amount only to voluntary departures from the general rule.

This thorough proficiency in practical matters tends largely to compensate for-in many cases to outweighthe deficiency in theoretical attainments; and it is undoubtedly this, influenced in some degree by the natural self-reliance and practical common sense inherent in the English character, which has given such a high standing to the profession in this country. The practical education in England is perhaps the most perfect possible, if the opportunities obtained during the pupilage are ample, and the pupil properly avails himself of them.

In marked contrast with this language comes the summary of the description of foreign engineering education.

The education of foreign engineers is strongly contrasted with that in England in every particular. Practical training by apprenticeship is unknown; the education begins at the other end, namely, by the compulsory acquirement of a high degree of theoretical knowledge, under the direction, and generally at the expense, of the
Government of the country. Partly with this, and partly afterwards, there is communicated a certain amount of information on practical matters; but this is imparted in a way differing much from the English plan, and probably with less efficient results.

Thus, while the English engineer is launched in his profession with the qualification of a considerable practical experience, but with perhaps little or no theoretical knowledge, the foreign one begins with a thorough foundation of principles, but with a limited course of practice; a deficiency, however, which tends to correct itself with time.

After a few paragraphs showing how these principles are worked out in various countries, we have a summary of suggestions made by engineers and others, without approval or condemnation. The body of the pamphlet consists of dry statistics, which would have been of greater value had not much of the matter been already published in various blue books; and at the end we find suggestions by individuals and extracts from published documents quoted, without any partiality for one rather than another.

It is very difficult to understand why the Council of the Institution has issued a document of this kind. Parents and guardians may find the list of schools and classes valuable, but neither the general public nor the engineers required information of the kind here given. Since the Paris Exhibition, we have been deluged with letters, pamphlets, and evidence as to foreign Polytechnic Schools. What we do require is some authoritative recommendation of one scheme. rather than another for raising the standard of engineering education in England. The Council may plead in extenuation of this grievous omission that they are not a legislative body; that their decisions would bind no one, and that they have always disclaimed all responsibility for the opinions expressed in the engineering papers which they publish. If they take no higher view of their functions than this, they might well have abstained from publishing this dry collection of statistics. If, on the other hand, they really mean that the education of young engineers in England needs no improvement, it is a pity that the opinion is not stated in so many words.

The language used conveys a mild expression of paternal approval of the good boys who "spontaneously elevate themselves to theoretical studies," but we almost see the bland smile of compassion with which the successful Nestor regards the proud enthusiasts.

We have the list of colleges where these good boys may be (spontaneousIy) diligent, but not a word indicating that the number of institutions is insufficient; that the number of classes in the institutions is in defect or excess of the requirements; far less any recommendation that engineers should make attendance on science classes compulsory instead of voluntary. We have an excellent short account of the Whitworth Scholarships, but no word of approval, no hope expressed that the example set may be followed. There is no suggestion that any new technical chairs are required, such as those lately founded in Manchester and Edinburgh, and we can well imagine that when other colleges or patrons approach Government asking for assistance to supplement local efforts, the Treasury may point to this pamphlet and say, Surely if the leading engineers in the kingdom are satisfied, we cannot be justified in giving you the assistance you ask.

No preference is indicated for Mr. Scott Russell's tremendous scheme, of Great Eastern proportions, no 
condemnation is hinted of collegiate education for our Indian engineers. Engineering degrees meet neither favour nor contempt; the gods of the profession seem to live far removed from all this turmoil, and do not deign even to nod approval.

Seriously, it seems impossible that the Council of the Institution can rest satisfied with such a contribution to the cause of education as this barren pamphlet. It is their duty to take action; their recommendations would have no legal force, but great moral weight. Let them say whether they desire great Polytechnic Schools on the continental model. Not improbably public money will ere long be granted for some such. Let them approve or condemn the Indian College. Let them recommend engineers to compel the attendance of their pupils at suitable classes, and to refuse all students as apprentices who cannot show that they have received proper preliminary training. If proper classes do not now exist for the students, let them tell us where they are wanted and what they ought to be. Let them declare what the preliminary training of a pupil must be. Let them fix a practical value on the engineering degrees of those colleges which deserve such encouragement; or finally, if they will do none of these things, let them say, if they dare, that they are perfectly well satisfied with things as they are.

\section{RECENT PETROGRAPHICAL LITERATURE}

II.

Untersuchungen ïberdie MikroskopischeZusammensetzung und Structur der Basalt-Gesteine. Von Dr. F. Zirkel. (Bonn, I870.)

Mikronineralogische Mittheilungen. Von Dr. F. Zirkel. Pp. 80I. (Neues Jahrbuch für Mineralogie, I870.)

Beiträge zur Petrographie der plutonischen Gesteine. Von Justus Roth. (Reprinted from the Transactions of the Royal Academy of Sciences of Berlin.)

Sur les Crystallites, études crystallogeniques. Par H. Vogelsang. (Archives Néerlandaises, 1870.)

Kritische Mikroskopisch-mineralogische Studien. Von $\mathrm{H}$. Fischer. (Freiburg.)

Mikroskopische Unterscheidung der Mineralien aus der Augit, Amphibole und Biotit-gruppe. Von G. Tschermak. (Proceedings of the Vienna Academy of Sciences, I869.)

$\triangle$ MONG the Continental petrographers who have led $A$ the way in the recent reform and extension of this branch of science, none can claim a more prominent place than Dr. Zirkel. Although still a young man, he has held professorships successively at Lemberg and at Kiel, and we rejoice to hear from him that he has been selected to succeed the venrrable Dr. Naumann at Leipzig. He is the author of many excellent mineralogical and petrographical papers, and of the best text-book of petrography which has yet been published. Especially has he distinguished himself by the zeal with which he has followed out the ideas first broadly sketched by Mr. Sorby, and has shown how absolutely indispensable is the application of the microscope to the study of the composition and history of rocks. His researches, while extending over the length and breadth of Germany, have not been confined to the Continent, but have been carried with cha- racteristic enthusiasm even as far as the peaks of Arran, and the cliffs and glens of our north-western isles.

A few years ago he resolved to devote himself to a comprehensive study of the rocks to which the general name of basalt has been given. Though abundant chemical analyses had made the ultimate chemical constitution of these rocks well known, the mineralogical composition of them still remained rather vaguely defined. Their compactness and dark opaque hue made it difficult to investigate the separate mineral ingredients of which they consisted, and men were still speculating about the mineralogical nature of that part of basalt which is soluble in acid, when Dr. Zirkel set to work to collect specimens of basalt from every available locality, and to prepare thin transparent sections of them for examination with transmitted light under the microscope. The result of these investigations appears in the little volume now before us, which is appropriately dedicated to Mr. Sorby. In a brief introduction the author recounts the state of the question when he took it up. Having collected and prepared upwards of 300 sections of basalt from the most varied localities, he believes that he has obtained samples of at least the chief types of composition and structure among the basalts, and he now gives us this first instalment of his labour.

The first section of the volume treats of the microscopic structure and peculiarities of the minerals which enter as chief ingredients into the composition of basait-augite, felspar, nepheline, leucite, olivine, magnetic iron, \&c. This is an especially valuable part of the book, seeing that it furnishes materials for speculating both upon the conditions under which basalt was erupted, and on the various metamorphic changes which the rock as a whole and its component minerals in particular, undergo under the influence of percolating water and atmospheric weathering.

The second part deals with the general microscopic structure of basalt-rocks. The common notion regarding that structure has hitherto been that down to its minutest particles basalt is a crystalline rock, that its individual microscopic ingredients mutually impinge on each other, and that the difference between the structure, for example, of granite and basalt consists in little more than in the varying relative size of their component minerals. Prof. Zirkel, however, shows that this notion, which has been founded on mere deduction and not on direct observation, must be changed. He finds that in the majority of the specimens examined by him, there exists between the most minute ingredients a more or less abundant substance, not individualised into crystals, but amorphous, acting like a cement, sometimes glassy in character, sometimes half-glassy, owing to the appearance of hair-like particles, and sometimes completely dentrified so as to present a confused aggregate of darker or lighter minute granules, needles, hair, and crystals. He regards it as hardly possible to doubt that this glassy base in basalt is the residuum of the original magma out of which the recognisable minerals in the rock crystallised, and that it furnishes us with a new proof of the igneous origin of basalt.

In the next section the author proceeds to offer a new subdivision, and detailed descriptions of the basalts. He bases his classification upon the mineralogical composition 